\title{
ФОНДОВЫЕ КРИЗИСЫ И ИХ РАННЯЯ ДИАГНОСТИКА
}

\author{
(c) 2019 Коновалова Мария Евгеньевна \\ доктор экономических наук, заведующий кафедрой экономической теории \\ Самарский государственный экономический университет, Россия, Самара \\ E-mail: mkonoval@mail.ru \\ (c) 2019 Кузьмина Ольга Юрьевна \\ кандидат экономических наук, доцент кафедры экономической теории \\ Самарский государственный экономический университет, Россия, Самара \\ E-mail: pisakina83@yandex.ru
}

Рассмотренные в статье вопросы возникновения фондовых кризисов и способов их диагностики являются актуальными, поскольку решение этих задач позволяет обеспечить экономическую безопасность страны. В статье рассмотрена сущность и содержание фондового кризиса, выявлены имманентно присущие ему черты. Значительное внимание уделено исследованию существующих методик качественной и количественной оценки фондовых кризисов. Авторами проведен анализ финансовых кризисов, имеющих место в российской экономики, показаны особенности их протекания и способы борьбы с ними. Обоснованы предложения и рекомендации по устранению существующих проблем российского фондового рынка с целью нивелирования угроз экономической безопасности страны.

Ключевые слова: финансовый кризис, фондовый рынок, фондовый пузырь, индикаторы финансового кризиса, экономическая безопасность

Динамика развития фондового рынка является достаточно четким индикатором существующих социально-экономических проблем. В последний ряд десятилетий количество финансовых кризисов существенно возросло, что обусловлено, во-первых, переходом к новой парадигме развития, основанной на приоритете финансового сегмента, во-вторых, общей глобализацией фондовых рынков, происходящей под влиянием стремительного роста информационных и цифровых технологий [1]. Для российского фондового рынка, несмотря на его относительную молодость, характерны все мировые тенденции, что говорит о его включенности в глобальный финансовый мир со всеми возможностями и ограничениями [2].

В 2005-2007 гг. прирост капитализации фондового рынка существенно опережал динамику ВВП, их соотношение достигло максимальных показателей. Такая ситуация свидетельствует о наличие пузыря на российском рынке, сдутие которого произошло вследствие обвала котировок ценных бумаг. После резкого обесценения в результате эффекта низкой базы в 2009 г. был достигнут максимальный темп прироста капитализации - 93\% на фоне снизившегося на 6\% ВВП. Такой аномально высокий темп роста рын- ка привел к формированию второго пузыря в 2010 г., хотя действительное значение Капитализация/ВВП превышает пороговое всего на 5\%.

На современном этапе показатель демонстрирует значение в пределах $42-43 \%$, что свидетельствует об отсутствии фондовых пузырей и сбалансированном соотношении фондового рынка и экономики страны.

При проведении факторного анализа цены актива ключевыми факторами, оказывающими влияние на динамику цен финансовых активов, были выбраны агрегат M2X, ставка межбанковского рынка MIACR, нефть марки Brent и доходность казначейских облигаций США - UST-10 [3].

Поскольку исследуемые ряды данных являются нестационарными (то есть их основные свойства остаются неизменными во времени), необходимо исследовать их на коинтегрируемость для корректности выводов о взаимозависимости между ними. Коинтегрированность является важным свойством многих экономических переменных, которое означает, что несмотря на случайный характер изменения отдельных экономических переменных, существует долгосрочная зависимость между ними, которая приводит к некоторому совместному, взаимосвязанному изменению. Тест Энгеля-Гранжара 
показал отсутствие коинтеграции в рядах MIBID и доходности UST-10 с индексом ММВБ, что указывает на статистически незначимое влияние данных факторов на динамику российского фондового рынка (табл. 1). Значит, включение этих факторов в модель будет нецелесообразным. Существенное влияние оказали два других фактора - M2X и Brent, поэтому дальнейшее моделирование будет основано на их использовании.

После оценки регрессии формируется двухфакторная модель, имеющая следующий вид:

$\ln ($ ММВБ $)=1,19+0,32 \cdot \ln (\mathrm{M} 2 \mathrm{X})+0,69 \cdot \ln ($ Brent $)$

Логарифмический масштаб был применен с целью соблюдения пропорций между уровнями ряда и приведения их к единой размерности.

Для более точной оценки пузыря определим долю пузыря (Bubble’s Part) в текущем значении индекса, рассчитав размер превышения рыночных значений индекса над получившимся модельными значениями. Результат нагляднее всего представить в виде графика (рис. 1).

В зарубежных исследования в качестве пороговых значений чаще всего выступают значения, не превышающие 5-10\% [5]. Однако такие низкие значения в большей степени применимы для развитых стран, а для высоко волатильного российского рынка, на наш взгляд, будет приемлем и наиболее оптимален пороговый уровень в $30 \%$ [4].

Исходя из полученных данных можно явно идентифицировать пузырь в 2006-2007 гг., когда значение Bubble's Part достигало 50\%. Были и ситуации, когда значения выходили за пределы нижней 30\%-й границы, то есть рынку была свойственна сильная недооцененность относительно фундаментальных уровней. Причем, после подобных моментов наблюдается быстрый рост котировок, который приводит к формированию пузырей. Весьма интересно выглядит то, что на данный момент значение индикатора приближается к верхней пороговой отметке. Это наводит на мысль о возможности формирования

Таблица 1. Коинтеграция индекса MOEX и исследуемых факторов

\begin{tabular}{|c|c|c|}
\hline Факторы & $\begin{array}{c}\text { t-статистика остатков } \\
\text { коэффициентов регрессии }\end{array}$ & $\begin{array}{c}\text { Наличие коинтеграции индекса } \\
\text { ММВБ и соответствующего фак- } \\
\text { тора }\end{array}$ \\
\hline M2X & $1,97(>1,94)$ & Есть \\
\hline MIBID & $1,42(<1,94)$ & Нет \\
\hline Brent & $2,84(>1,94)$ & Есть \\
\hline UST-10 & $1,64(<1.94)$ & Нет \\
\hline
\end{tabular}

Источник: составлено авторами на основе проведенных расчетов.

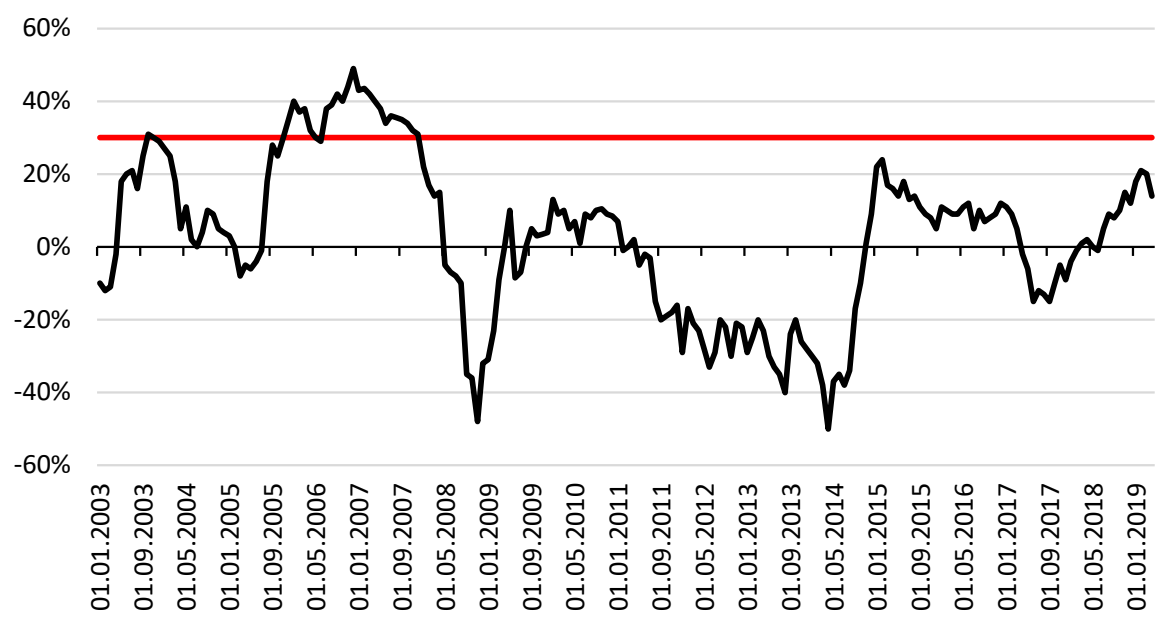

Puc. 1. Динамика Bubble's Part для индекса MOEX

Источник: составлено авторами на основе проведенных расчетов 
нового финансового пузыря, особенно в условиях достижения индексом новых исторических максимумов за недавнее время. Однако схожая ситуация наблюдалась в 2015 г.- индикатор также был близок к пороговому значению, но в итоге так его и не достиг.

Что касается фрактального анализа рынка. То были получены следующие результаты. За исследуемый период было выявлено три периода, когда показатель Херста соответствовал критерию «фрактального шума» (рис. 2). Первая сигнальная точка была отмечена в начале 2006 г. Прирост индекса ММВБ тогда составил 220\%, что явно свидетельствует о бычьей динамике. Это стало причиной перехода рынка в состояние самоорганизованной критичности. Похожая ситуация произошла в 2011 г., величина индикатора также составила 0,79 . Наиболее сильный «катастрофический шум был зафиксирован в
2008 г.- значение показателя Херста достигло максимального уровня за весь период $(0,87)$, что явно сигнализировало о предкризисном состоянии рынка.

Данный анализ позволил сделать вывод, что российский фондовый рынок действительно обладает долговременной памятью. Как только показатель приближается к пороговому значению, рынок «вспоминает» предыдущую динамику и стремится повторить ее. В марте 2019 г. показатель Херста составил 0,71, что весьма близко к границе, но пока говорить о возможности катастрофы не приходится.

Для наиболее полной интерпретации полученных результатов сопоставим пороговые значения каждого индикатора с действительными и продиагностируем рынок на наличие фондового пузыря в 2018-2019 гг. (с последнего дна в 2017 г.) (табл. 2). В качестве полученных значе-

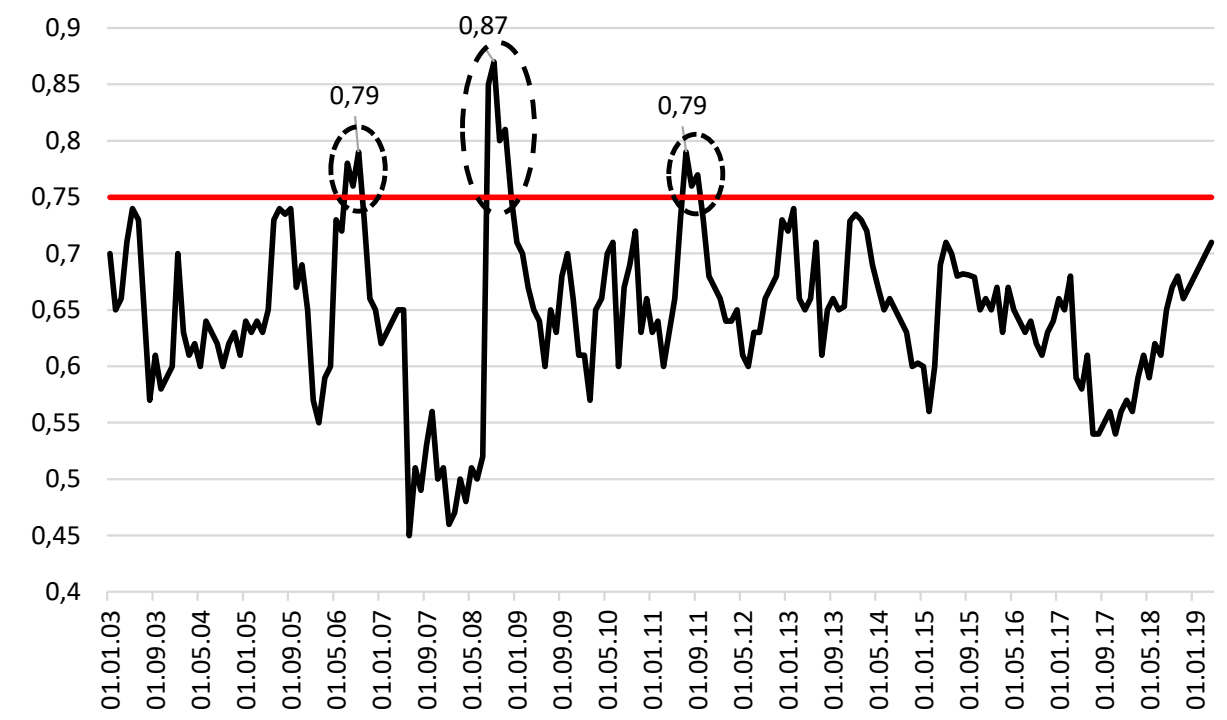

Puc. 2. Динамика показателя Херста

Источник: составлено авторами на основе проведенных расчетов

Таблица 2. Результаты комплексного анализа по идентификации фондовых пузырей на современном этапе

\begin{tabular}{|c|c|c|c|}
\hline & Полученные значения & Пороговые значения & $\begin{array}{c}\text { Вероятность } \\
\text { возникновения пузыря }\end{array}$ \\
\hline $\begin{array}{c}\text { Тест рынка на информа- } \\
\text { ционную эффективность }\end{array}$ & $\begin{array}{c}6 \text { лаг }-2,286 \\
7 \text { лаг }-2,291 \\
8 \text { лаг }-2,311\end{array}$ & $1,715<\mathrm{DW}<2,284$ & есть \\
\hline $\begin{array}{c}\text { Макроэкономический } \\
\text { анализ }\end{array}$ & $42 \%$ & $62 \%$ & нет \\
\hline Факторный анализ & $21 \%$ & $30 \%$ & нет \\
\hline Фрактальный анализ & 0,71 & 0,75 & \\
\hline
\end{tabular}

Источник: составлено авторами на основе проведенных расчетов 
ний используются максимальные значения за указанный период.

Лишь один из четырех индикаторов показал возможность формирования пузыря на российском рынке - тест Дарбина-Уотсона на информационную эффективность. Остальные же индикаторы говорят об отсутствии такой возможности. Однако некоторые из них достаточно близки к границе. Например, полученное значение при факторном анализе всего на 9\% ниже порога. Учитывая эффект информационной каскадности и весьма хорошую динамику рынка в последнее время, эти 9\% могут быстро сойти на нет. Фрактальный анализ также демонстрирует близость расчетного и порогового значений, а значит если Н-коэффициент достигнет 0,75-го уровня в ближайший промежуток времени, то рынок с большей вероятностью проиллюстрирует формирование пузыря.

Результаты анализа макроэкономической среды свидетельствуют об экономически обоснованном соотношении размеров фондового рынка и ВВП страны в марте 2019 г., с точки зрения идентификации пузырей. Доля фондового рынка в экономике составила $42 \%$ в сравнении с максимально допустимой - 62\%. Значит, в таких условиях формирование последних мало вероятно.

В процессе исследования на отечественном фондовом рынке была выявлена важная особенность в формировании пузырей: каждому из диагностированных пузырей предшество- вали интервалы с заниженными ценами акций относительно их справедливых значений, то есть наблюдалась существенная недооцененность индекса ММВБ. В промежутках времени, в которых колебание индекса происходило на околофундаментальном уровне, формирование пузырей не происходило. Из этого следует, что возможной предпосылкой необоснованного роста уровней индекса выступает систематически заниженная стоимость активов, которая привлекает инвесторов к спекулятивному выкупу, что в конечном итоге приводит к надуванию пузыря. Поскольку за последние два года существенной недооцененности не наблюдалось, это не должно вызвать аномально высоких темпов роста индекса.

Таким образом, в результате реализации комплексного анализа фондового пузыря были сделаны следующие выводы.

Во-первых, построенная модель адекватно отражает сформированные ранее фондовые пузыри, что доказывает пригодность в ее использовании.

Во-вторых, модель характеризует разные стороны фондового рынка: Выявление отклонений в какой-либо из сфер будет сразу указывать на причины возникновения аномалий на фондовом рынке. Например, на современном этапе основная проблема рынка акций носит поведенческий характер, то есть имеется склонность к коллективному действию участников.

\section{Библиографический список}

1. Михайлов А.М., Пономарева М.В. Инновационные решения на фондовом рынке //Экономические науки. 2019. № 178. C. 51-54.

2. Balke, N., Wohar, M. Market fundamentals versus rational bubbles in stock prices: A Bayesian perspective// Journal of Applied Econometrics. - 2009. - № 24(1). - P. 35-75.

3. Flood, R.P., Hodric, R.J. An Evaluation of Recent Evidence on Stock Market Bubbles // NBER Working Paper.1986. - № 1971._- P. 1-48. - URL: http://www.nber.org/papers/w1971.pdf, (дата обращения: 17.03.2019)

4. Diba, B., Grossman, H. Explosive Rational Bubbles in Stock Prices// AER. - 1988. - № 78(3). - P.520-530. - URL: https://www.researchgate.net/publication/254072432 (дата обращения: 17.03.2019)

5. Деревщикова, Е.О.Финансовый кризис 2014-2015 гг.: последствия и перспективы для России// Международный журнал социальных и гуманитарных наук. - 2016. - № 1.- С. 25-28. 